\title{
Consumers' perceptions and preference profiles for wood surfaces tested with pairwise comparison in Germany
}

\author{
Andreas Manuel • Rainer Leonhart • Olof Broman • \\ Gero Becker
}

Received: 25 July 2014 / Accepted: 26 December 2014 / Published online: 16 January 2015

(C) INRA and Springer-Verlag France 2015

\begin{abstract}
- Key message Visual aspects of wood are appreciated in interior design and many other high-end applications. This study focuses on consumer preferences which are examined regarding visually different spruce floor samples. Results indicate specific market segments according to different consumer preference groups.

- Context Wood for interior use is attractive to many consumers for aesthetic and ecological reasons. Visual attractiveness can be decisive for high added value. Industrial wood grading based on technical parameters is a common practice,
\end{abstract}

Handling Editor: Jean-Michel Leban

Contribution of the co-authors Andreas Manuel: processing digital image data, data acquisition and designing online questionnaires, data analysis, writing the paper

Rainer Leonhart: supervising research design (survey studies), supervising statistical data analysis

Olof Broman: supervising the online surveys and image processing, revising the manuscript

Gero Becker: overall concept of the project, supervising the work, revising the manuscript

\section{A. Manuel $(\bowtie) \cdot \mathrm{G}$. Becker}

Chair of Forest Utilization, Faculty of Environment and Natural

Resources, University of Freiburg, 79085 Freiburg, Germany

e-mail: andreas.manuel@fobawi.uni-freiburg.de

G. Becker

e-mail: gero.becker@fobawi.uni-freiburg.de

\section{R. Leonhart}

Social Psychology and Methodology, Institute of Psychology,

University of Freiburg, 79085 Freiburg, Germany

e-mail: leonhart@psychologie.uni-freiburg.de

\section{O. Broman}

Division Wood Science and Engineering, Department of Engineering Sciences and Mathematics, Luleå University of Technology, SE-931

87 Skellefteå, Sweden

e-mail: olof.broman@1tu.se but little is known about consumer preferences which could direct the production chain from the tree to the final product presented to the consumer.

- Aims In this study, two objectives are addressed: (1) reducing the complexity of wood appearances based on consumers' perceptions and (2) aggregating diverging preferences to consumer groups.

- Methods Four hundred twenty-five boards from spruce logs were classified on the basis of their visual appearance. Fifteen visual classes of these boards were identified. From each of these classes, a representative floor sample was made with dimensions of $2 \mathrm{~m} \times 1 \mathrm{~m}$ and a high-resolution image taken of it. These 15 images were then evaluated by consumers and grouped using multidimensional scaling. Finally, consumer preference profiles were analysed on the basis of latent class analysis.

- Results The first main result is that from the initial 15 classes which arose from the visual board sorting, consumers could objectively only distinguish seven from each other. The second main result is that among these seven classes, five of them were identified as the most liked.

- Conclusion This contribution provides an objective methodology for the assessment of the visual preference of wooden products that may pave the avenue to more efficient allocation of the selected end products to the targeted groups of consumers.

Keywords Consumer preferences · Perception of wood surfaces $\cdot$ Spruce wood floors $\cdot$ Picea abies

\section{Introduction}

Besides its common use for construction and packaging, wood is also an aesthetically highly appreciated material used in many high-end applications like furniture and interior design. The presence of visible wood surfaces causes an overall positive impression (Rice et al. 2006; Ridoutt et al. 2002). 
Among German consumers, Gold and Rubik (2009) found that wood is associated with the attributes of well-being, aesthetics and eco-friendliness. Moreover, it is considered a natural material (Nyrud and Bringslimark 2010) and environmentally friendly (Pakarinen 1999), aspects that have become more important in recent years. To fully explore the chance to 'translate' this high appreciation into added value, manufacturers should know more about the tastes and preferences of potential consumers. Based on this knowledge, their production-technology and product design could be directed more precisely towards the wishes and preferences of the consumers.

Due to the fact that most solid wood is used in construction, the sorting and classification procedures used by the industry primarily aim at technical properties. Technical properties which relate to use in this area are e.g. strength, elasticity, dimensional stability, etc. (Kretschmann 2010). In general, this leads to a situation where 'clear' types of solid wood receive a higher grade whereas all kinds of structural deviations (knots, grain orientation, cracks) are regarded as 'defects' and consequently receive a lower grade or are even rejected. This also limits the variety in the finished wood products because of the absence of or the minimal appearance of technical defects like knots or cracks required (DIN EN 1611-1:2002-11). Accordingly, this sorting and classification practice does not at all take into account optical surface parameters which might be decisive in attracting consumers. There are only few studies which link individual appearance of surfaces to consumers' preferences. Nyrud (2008) found that wood surfaces should have a homogeneous visual appearance. Broman (1995b) found that diverging/mismatching wood features are more important for people's evaluation than the overall look of a wood surface. Other findings indicate people's appreciation of wood and how they describe it using subjective criteria like e.g. 'warm', 'natural' and 'harmonious' (Broman 1995a; Nordvik et al. 2010).

It can be stated that the knowledge about existing consumer preference groups is assumed to be often vague (Scheer et al. 2008). Today's sorting practices in the wood processing industries as well as customized requirements are rarely adjusted to consumer preferences (Pakarinen 1999; Weinfurter and Hansen 1999). Besides consideration of norms and rules, customization is a common process regarding specific product requirements of business customers in contrast to consumer orientation. It has been found that retailers and consumers even describe their preferences differently (Bumgardner et al. 2001). Regarding consumer's perception of wood surfaces, it has been found that special wood features in contrast to clear surfaces are considered important aesthetic features in cabinet doors (Donovan and Nicholls 2003). This might indicate the relevance of the presence or absence of, for instance, knots to determine different preference classes. As found by Marchal and Mothe (1994) in France, diverging preferences could be identified where one group preferred clear surfaces and another group preferred slightly knotty surfaces (small knots). From a preference study of Malagasy consumers, Ramananantoandro et al. (2013) conclude that aesthetic features like colour and texture and the density of furniture wood species have an effect on consumers' preferences. Hoibo and Nyrud (2010) suppose harmonious and homogeneous surfaces are preferred by consumers which are achieved with few knots and even knot patterns in visual product surfaces.

Ultimately, it can be stated that the first prerequisite to achieve a higher added value on solid wood in the high-end market segment is to (1) learn more about the preferences of end-consumers regarding wood surfaces. Based on this information, these (subjective) judgements can (2) be 'translated' into measureable and quantifiable parameters of the desired end product(s) and (3) allow the whole production and transformation process from the $\log$ to the final product to be directed accordingly. This study has focused on learning more about people's preferences on wood surfaces. Derived from an individual tree, every solid wood surface (e.g. board surface) has its unique features, and every consumer might have a different appreciation for it. Obviously, a sorting approach which is totally individualized according to individual wood surfaces and individual consumer preferences is not feasible for practical product design and marketing.

For this study, two explorative survey studies were conducted in order to group and classify (1) wood surfaces according to their similarity and (2) consumer groups according to their preferences. The first part of this article discusses the first study in which consumers judged different wood surfaces and grouped them according to their visual similarity. In the second part, the results from the preference study and the visual surface classes derived from those results are presented. In both parts of the study, the same material (wooden floor surfaces) was used for the empirical tests.

\section{Materials and methods}

\subsection{Wood surface samples}

To test both the similarities of wood surfaces and consumer preferences for them, solid wood samples were prepared and used in both parts of this study. Wooden floorings were chosen as example products to be studied. Floors have large surfaces which provide the opportunity to present wood in different aspects and facets. Since the samples should comprise a wide range of different structural and optical wood features with its typical high natural variability, sawn boards from 57 Norway spruce logs (32 trees) (Picea abies [L.] Karst.) were selected for this study.

The logs came from both lower and upper tree sections and had mid-diameters between 30 and $50 \mathrm{~cm}$. A total of 810 floor 
boards were produced in an industrial sawmill with raw sawn board dimensions of 130-mm width, 30-mm thickness and 4000-mm length, which allowed after drying a standard dimension of $100-\mathrm{mm}$ visible width of the final product. The sawmill's own standards of grade A (vertical grain) and grade B (flat grain) were assigned to these boards with regard to a standard product length of $3 \mathrm{~m}$ for floor board production.

To identify distinct visual classes among the available material, a more sophisticated visual sorting was applied. Scientific experts visually examined the full pile of 810 boards and identified those boards that would hold a minimum of $2-\mathrm{m}$ product length of accepted (technical) quality for flooring. This product length was chosen so as to fit the floor samples (height $2 \mathrm{~m}$, width $1 \mathrm{~m}$ ) that were going to be presented to consumers in the subsequent similarity and preference tests. In total, 385 boards were rejected due to significant mechanical defects like splits, holes, rot etc. The 425 technically accepted boards were grouped due to their visual characteristics. The experts grouped each board according to its surface features like grain orientation, colouration (compression wood) and knot characteristics. As found by Nicholls and Barber (2010), character marks, grain consistency and colour are important attributes for consumers' assessments. The experts' primary consideration when sorting the boards was their grain consistency (vertical/rift grain and flat grain) and proceeded by sorting with regard to knot features (e.g. sound knots, black knots) and other visual features like compression wood and pith. This preliminary sorting took neither sorting rules nor a specific numbers of classes into account. Boards were grouped into distinct and visually homogeneous classes. After the experts' manual inspection of each board from two ends, a number of 15 different visual classes could be determined. Five classes were identified among boards that were presorted to a pile of vertical grain. In the flat grain group, including boards from the log centre, ten classes were identified. All visual classes found and the frequency distributions of the boards are described in Table 1.

From each visual class, one representative floor sample (length $2 \mathrm{~m}$, width $1 \mathrm{~m}$ ) was produced with ten selected boards (length $2000 \mathrm{~mm}$, width $100 \mathrm{~mm}$ ). Each floor sample was produced out of ten boards in order to produce a maximum level of homogeneity with regard to their visible features, e.g. knots or colouration that each single board held. Colour consistency and grain pattern consistency are quoted as requirements for high-end veneer production (Wiedenbeck et al. 2004). The aim with this composition was to avoid negative judgements of respondents that might be caused by a single, visually mismatching board. Digital images of the 15 representative floor samples (Fig. 1) were produced from the digital single board image data acquired with an RGB line camera positioned on the industrial board scanner during the production process at the sawmill. The colour image data presented was processed digitally, and single board images were
Table 1 Visual appearance classes of 425 boards assessed by wood experts. The perceived look of the board surfaces in each class is described according to the experts' sorting decision

\begin{tabular}{|c|c|c|}
\hline Visual class & Number/class & Description \\
\hline 1 & 40 & Vertical grain, clear surface, no knots \\
\hline 2 & 24 & Vertical grain, few small black knots \\
\hline 3 & 58 & $\begin{array}{l}\text { Vertical grain, few small to medium } \\
\text { black knots }\end{array}$ \\
\hline 4 & 15 & Vertical grain, big sound knots \\
\hline 5 & 30 & $\begin{array}{l}\text { Vertical grain, compression wood } \\
\text { (colour variation), stripy }\end{array}$ \\
\hline 6 & 24 & Flat grain, few small black knots \\
\hline 7 & 16 & $\begin{array}{l}\text { Flat grain, high contrast in flat grain } \\
\text { background structure }\end{array}$ \\
\hline 8 & 13 & Flat grain, extra big sound knots \\
\hline 9 & 26 & $\begin{array}{l}\text { Flat grain, blurry background structure, } \\
\text { medium black knots }\end{array}$ \\
\hline 10 & 36 & $\begin{array}{l}\text { Flat grain, pith and longitudinal cut } \\
\text { centre knots }\end{array}$ \\
\hline 11 & 9 & Flat grain, small to medium black knots \\
\hline 12 & 27 & $\begin{array}{l}\text { Flat grain, small sound knots, decent } \\
\text { background structure, calm }\end{array}$ \\
\hline 13 & 28 & $\begin{array}{l}\text { Flat grain, pale background structure, } \\
\text { various knot types }\end{array}$ \\
\hline 14 & 29 & $\begin{array}{l}\text { Flat grain, vivid, sound knots, marbling } \\
\text { background structure }\end{array}$ \\
\hline 15 & 50 & $\begin{array}{l}\text { Flat grain, big sound knots in longer } \\
\text { distances }\end{array}$ \\
\hline Total & 425 & \\
\hline
\end{tabular}

assembled to the floor samples of 600 pixels height and 300 pixels width. Small adjustments were applied on the raw image data in brightness $(+60)$ and in the colour channels $(\mathrm{R}+71, \mathrm{G}+6, \mathrm{~B}-36)$ to reach that colour composition presented in Fig. 1.

\subsection{Methods}

There were two main goals during this project: to test if consumers recognize visual similarity of different wood surfaces (study 1) and to test the preferences of consumers towards different wood surfaces (study 2). Earlier research has revealed that images of wood surfaces can be used to examine people's perception (Broman 1996). Therefore, both studies were designed as online surveys in order to reach many interview persons. People were invited via public platforms (e.g. on the web page of our institute) and email. The email invitations were sent to people who had shared their email addresses in earlier studies agreeing to participate in future studies. Furthermore, people working in wood-related organizations as well as employees and students of our university (University of Freiburg) were encouraged to participate. 


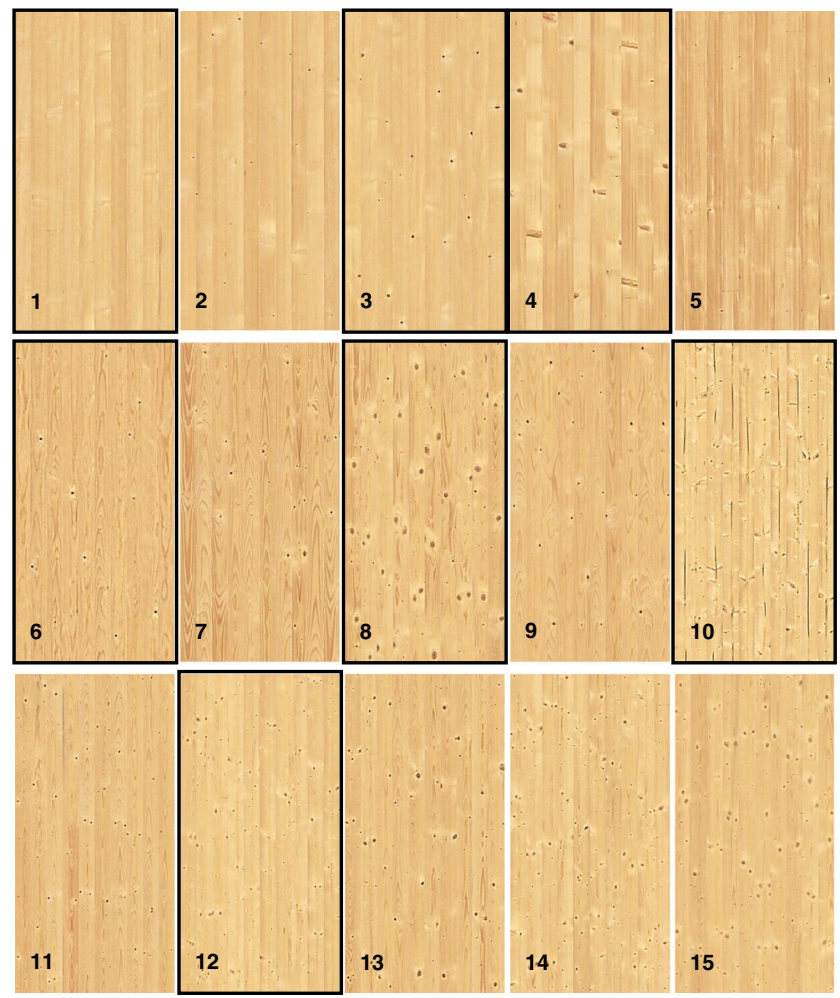

Fig. 1 Fifteen Norway spruce floor samples each composed of ten single floor boards, representing 15 visual classes (see Table 1). The images presented online represent floor samples of originally $2-\mathrm{m}$ height (600 pixels) and 1-m width (300 pixels). The framed samples were used in the consumer preference test

To test the similarity of different floor samples (study 1) and to test people's preferences (study 2), two separate and independent groups of individuals were invited. Thus, two different response samples were analysed.

\subsection{Study 1 - similarity test}

To address the first study question of grouping boards according to their similarity of visual appearance, an online survey was first carried out. The aim was to explore whether the 15 classes determined by the experts might also be reflected in end users' perceptions. A second (more technical) objective of this similarity study was to reduce this number of visual classes. On the basis of this reduced number of classes, a preference study would then be carried out. In the online similarity test survey, the 15 floor images were judged pairwise regarding their similarity based on the seven-point Likert scale (from $1=$ low similarity to $7=$ high similarity). A complete questionnaire led to 105 decisions (pairwise combinations) from each respondent. The questionnaire was published in German, in Germany.

By using multidimensional scaling (MDS), the visual similarity between the tested images was examined. Based on a proximity matrix, MDS calculates Euclidian distances between the tested objects while a number of underlying dimensions are found (Hair et al. 2010). To evaluate the model's accurateness, Kruskal (1964) provides as a rule of thumb a stress measure (Stress1) that is minimized by increasing the number of dimensions with 0.4-poor, 0.2-fair, 0.1good, 0.05-excellent and 0.0-perfect. A squared correlation index (RSQ) was calculated as an index of fit indicating the proportion of variance disparities that is explained by a number of extracted dimensions with RSQ values of 0.9 and higher. These values are considered the best. MDS was computed applying ALSCAL (Young and Lewyckyj 1979) in IBM SPSS Statistics 22 (IBM Corp. Released 2013).

\subsection{Study 2 - preference test}

Addressing the second study question based on the preceding findings, respondents' preferences were tested in a second online survey. In this study, preferences were expressed as decisions made in pairwise comparisons which led to ranking profiles specifying preference orders of the tested stimuli from 'like most' to 'like least'. To do so, floor images were presented on screen pairwise and in different combinations. Each time, one of the two images presented was to be assessed as preferred or rejected in relation to the other. To examine the results, preferences and differences among groups of people, a latent class analysis (LCA) was performed. To be able to test people's ranking profiles in a LCA, the binary data was translated into ranking data (ordered categories) from rank $1=$ 'like most' to rank $7=$ ='like least'. Latent class analysis was computed with Mplus (Muthén and Muthén 19982011). Inconsistent responses like tied ranks or ring closures (example: $\mathrm{a}>\mathrm{b}, \mathrm{b}>\mathrm{c}$ and $\mathrm{c}>\mathrm{a}$ ) prevented a clear ranking order. In our study, the problem of such inconsistent responses which resulted in tied ranks was solved as follows:

- Recoding paired data (preference decision for image 1 or 2 of a pair) to 1 and -1 considering the decision for each single image that leads to a doubled number of new variables from a pair decision to single decisions $(+1=$ like, $-1=$ dislike).

- Calculating weights to solve tied ranks: Sum the winnings $(+1)$ per image. Weight $=$ sum of winnings $/ \mathrm{n}$ ( $\mathrm{n}$-decisions per image).

- The new variables (values $1,-1$ ) were multiplied with the weights. The actual weight for each multiplication was therefore provided by the opposite image from the original pairwise comparison (pairwise preference decision).

- The sum of the weighted values for each image (weighted values: $(+1) \times$ weight, or $(-1) \times$ weight) was then used to bring the tested images into a ranked order.

To solve tied ranks, weights were calculated for each decision, trying to identify conclusive decisions in the original 
data that help to determine the ranking order. The weights are multiplied with the actual value, and the sum of the weighted values for each image is the base to order the tested images into ranked order. Only if unsolvable ring closures exist does this procedure fail. Unsolvable cases are excluded in further analysis.

Differences between respondents are revealed by their preference profiles (ranking order of images). Individuals with similar assessment results are grouped into the same latent class. Through LCA, the minimum number of latent classes is determined where information criteria determining the model's accurateness should be at a local minimum. The Akaike information criterion (AIC, Akaike 1987) and the Bayesian information criterion (BIC, Schwarz 1978) are used as test criteria. These criteria indicate specific differences between classes with respondent-specific preference profiles (Geiser 2011). While AIC and BIC are indicators for an optimal solution, chi-square is not considered, but is nevertheless presented as a descriptive measure of the models' fit (cf. Jöreskog 1993).

\section{Results}

\subsection{Study 1 - similarity test}

The completed online evaluations of 112 respondents (59.9\% of $n=187$ total) are analysed to examine the similarity between the 15 initially presented images through a multidimensional scaling procedure. Out of the participants, $59(53 \%)$ were male and $53(47 \%)$ female. Their average age was 32 years (min. 21, max. 63, SD 10.50). Out of the respondents, $27(24 \%)$ reported they were wood experts.

In order to perform multidimensional scaling, different dimensional solutions were calculated and validity measures compared. RSQ values indicate that already two dimensions (Stress1 0.16, RSQ 0.90) provide a good fit (>0.9). Furthermore, Kruskal's Stress1 values (Kruskal 1964) indicate an elbow at two dimensions but including a third dimension improves the results to some extent (Stress1 0.09, RSQ 0.96). Hence, a three-dimensional solution was chosen with little unexplained variance remaining. The spatial configuration (perceptual maps) of the three-dimensional solution is presented in Fig. 2. In images 1 and 8 and images 4 and 6, the poles of the first and second dimensions, respectively, are recognizable as seen in the comparison map of these two dimensions. In the corresponding map of dimensions 1 and 3 , images 3 and 10 are identifiable as the poles of dimension 3 . Image 12 is located close to the centre in all three maps according to the respondents' evaluations of similarity and was therefore chosen as the floor sample with an appearance of intermediate visual characteristics such as small sound
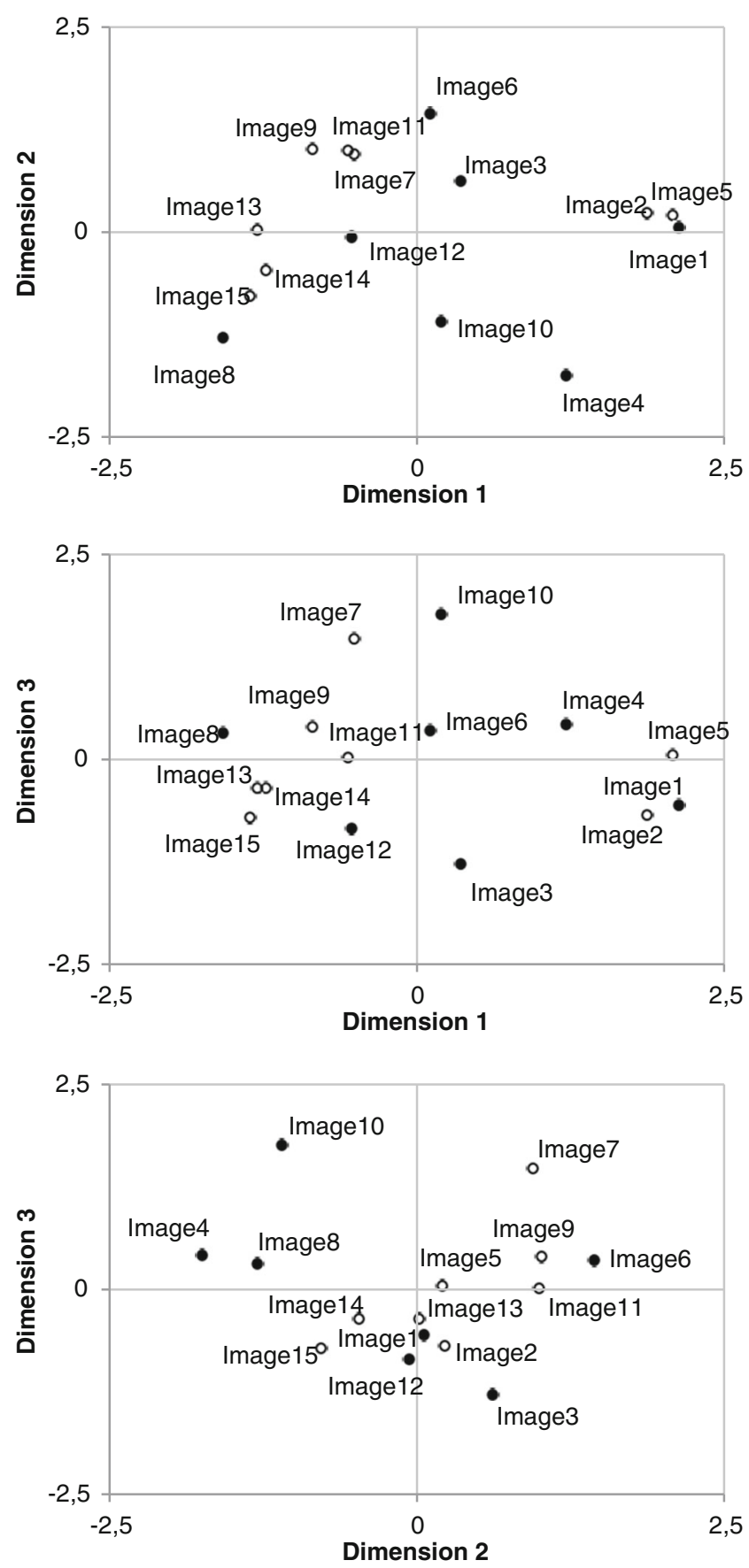

Fig. 2 The spatial configurations of tested stimuli within a threedimensional solution retrieved through MDS. The selected images used in the preference test are highlighted by the filled circle

knots among the other classes of vertical and flat grain. Image 12 was selected to complement the visual range of the other selected images. The resulting selection of seven visually different image classes is represented by the images $1,3,4$, 6, 8, 10 and 12, and they are highlighted (framed) in Fig. 1. Thus, based on the consumer evaluations, these seven image classes are defined by the six poles from MDS which stand for the lowest level of similarity. The visual class 12 represents a 
complement from near the log centre. Therefore, this class and the poles represent distinct visual aspects in wood surface appearance. The images 2, 5, 7, 9, 11, 13 and 14 were regarded as being too similar to others to justify an extra visual class to test in study two.

\subsection{Study 2 - preference test}

To study differences in people's preferences, participants were asked to evaluate the seven visually distinct floor samples which were identified in the similarity test (study 1). People were asked to evaluate their preferences towards floor samples presented pairwise. Results led to preference profiles with tested images in a rank order.

This online study resulted in 504 completed responses. The result of each respondent is a preference profile from rank $1=$ 'like most' to rank 7='like least'. Among a total of 110 inconsistent responses, 81 cases showed insolvable ring closures, but 29 cases were solvable tied ranks, leaving 423 valid responses for further analysis.

Besides the pairwise ranking task, socio-demographic data was requested for sample description and filled in completely by $379(89.6 \%)$ respondents. Participants of the preference study had an average age of $38.80(\min .=17$, max. $=77, \mathrm{SD}=$ 13.80). When asked about their current occupation, people reported as follows: business employee $43.9 \%$, student $24.7 \%$, public servant $17.9 \%$, self-employed $6.1 \%$ and others $7.4 \%$. To the question whether one's occupation is related to wood, 214 respondents $(56.3 \%)$ answered positively. Ninety-seven $(25.5 \%)$ people stated they were a wood expert.

Overall preference (ranking) results are presented in Table 2, where for instance distinct bimodal distributions are observed for the floor images 1 and 8 .

To reveal differences in the preferences among the respondents and to create groups of respondents ('classes') with similar preferences, results were analysed further using latent class analysis (LCA) based on ordered categorical data. In
Table 3, the quality of the model is examined. The AIC measure indicates a local minimum at seven classes. Whereas BIC and degrees of freedom presented in Table 3 give no clear indication for an optimal solution. To complement the descriptive outcome from LCA, the chi-square is also presented in Table 3. Thus, seven latent classes (LC), i.e. preference groups, are found to be the appropriate basis for further analysis. If the respondents in this study are classified into seven latent classes, the probabilities of correct classification (Table 4 ) are then $>0.9$ ( 0.93 to 0.97 ) in all latent classes which is considered as good (Rost 2006). The analysis of the preference data according to the social-demographic items of the respondents did not reveal any significant differences inside the preference classes.

An average ranking of the images within each of the seven latent classes is presented in Fig. 3. The ranking results indicate appreciation and rejection, or rather intermediate assignment for each latent class. Looking for extremes in the preference orders (profiles) can help to identify the class-specific characteristics. Five images were found to have class maxima: image 1 (LC5 and LC7), image 3 (LC1), image 4 (LC2), image 6 (LC3) and image 8 (LC4 and LC6). No class maxima are found for the images 10 and 12. Class minima are found for image 1 (LC6 and LC4), image 3 (LC2), image 8 (LC1 and LC7) and image 10 (LC3 and LC5). Images 4, 6 and 12 are not ranked as class minima. Details of the ranking results for the different consumer preference groups are given in Table 4.

LCA respondents were grouped according to a certain degree of accordance in their assessment behaviour. It can be assumed that respondents grouped in one class share similar preferences for certain visual aspects of the presented floor samples. Figure 4 presents for each LC the detailed ranking results within this respective class as histograms of relative frequencies. Five images received unanimously high agreement for specific ranks. This is found in LC1 (image 8, rank 7), LC3 (image 3, rank 3), LC5 (image 10, rank 7), LC6 (image 1, rank 7) and LC7 (image 1, rank 1). The results for LC2 and

Table 2 Ranking frequencies in seven tested images $(N=423)$ and average rankings

\begin{tabular}{|c|c|c|c|c|c|c|c|c|}
\hline & & Image 1 & Image 3 & Image 4 & Image 6 & Image 8 & Image 10 & Image 12 \\
\hline Rank 1 & $N(\%)$ & $157(37.1)$ & $11(2.6)$ & $50(11.8)$ & $57(13.5)$ & $88(20.8)$ & $31(7.3)$ & $29(6.9)$ \\
\hline Rank 2 & $N(\%)$ & $48(11.3)$ & 75 (17.7) & $53(12.5)$ & $92(21.7)$ & $53(12.5)$ & 49 (11.6) & $53(12.5)$ \\
\hline Rank 3 & $N(\%)$ & $28(6.6)$ & $90(21.3)$ & $68(16.1)$ & $89(21)$ & $27(6.4)$ & $39(9.2)$ & $82(19.4)$ \\
\hline Rank 4 & $N(\%)$ & $30(7.1)$ & $72(17)$ & 79 (18.7) & $57(13.5)$ & $41(9.7)$ & $52(12.3)$ & $92(21.7)$ \\
\hline Rank 5 & $N(\%)$ & $31(7.3)$ & $66(15.6)$ & $66(15.6)$ & $61(14.4)$ & $38(9)$ & $63(14.9)$ & $98(23.2)$ \\
\hline Rank 6 & $N(\%)$ & $34(8.0)$ & $85(20.1)$ & $63(14.9)$ & $48(11.3)$ & $56(13.2)$ & $94(22.2)$ & $43(10.2)$ \\
\hline Rank 7 & $N(\%)$ & $95(22.5)$ & $24(5.7)$ & $44(10.4)$ & $19(4.5)$ & $120(28.4)$ & $95(22.5)$ & $26(6.1)$ \\
\hline \multicolumn{2}{|c|}{ Mean ranking } & 3.50 & 4.08 & 4.00 & 3.46 & 4.27 & 4.72 & 3.97 \\
\hline
\end{tabular}

Figures highlighted in italics illustrate local maxima in bimodal distributions 
Table 3 Results of information criteria to evaluate the model quality for different numbers of latent classes

\begin{tabular}{lllll}
\hline Iterations & $\begin{array}{l}\text { Akaike } \\
\text { (AIC) }\end{array}$ & $\begin{array}{l}\text { Bayesian } \\
\text { (BIC) }\end{array}$ & $\begin{array}{l}\text { Chi- } \\
\text { square }\end{array}$ & $\begin{array}{l}\text { Degrees of } \\
\text { freedom }\end{array}$ \\
\hline 3 classes & $10,490.40$ & $11,008.46$ & 8016.85 & 823,129 \\
4 classes & $10,350.24$ & $11,042.34$ & 7751.54 & 823,095 \\
5 classes & $10,307.24$ & $11,173.38$ & 7664.02 & 823,054 \\
6 classes & $10,293.18$ & $11,333.36$ & 7144.25 & 823,022 \\
7 classes & $10,261.03$ & $11,475.24$ & 8702.18 & 822,984 \\
8 classes & $10,289.55$ & $11,677.80$ & 8795.59 & 822,941 \\
\hline
\end{tabular}

LC4 indicate a more evenly distributed ranking for all images. The determination of a certain but less pronounced preference is still possible through the average assessment presented in Fig. 3; all images are ranked in the middle range; extreme ranks are missing.

\section{Discussion}

Experts with scientific background in wood quality sorted a total of 425 technically feasible floor boards into 15 classes. Floor sample images of these 15 floor classes were evaluated by 112 respondents online. Through multidimensional scaling, it was possible to define seven different groups of images to be used in a preference study and the result may also be useable for floor marketing in Germany. The results indicate that seven different sorting classes of spruce wood could be visually differentiated by the survey participants. Producers and retailers can benefit from these findings in developing new products of valuable wood surfaces based on consumers' similarity judgements and so complement and enhance their product portfolios of different appearances from the same wood species.

The number of 112 respondents in study I may not be sufficient to represent a realistic range of different 'floor consumers', but helped to explore the sense of similarity among consumers as an exploratory study. In comparison with future studies, the results can be validated also with regard to increased generalizability (Hair et al. 2010). A differentiation of the judgement according to social parameters (gender, age, professional background and wood experience) did not reveal significant differences. However, the respondents' evaluations of similarity between the 15 image classes initially determined by the scientific experts (Table 1) led to a substantial reduction into seven classes. This supports the hypothesis that consumers might base their judgement of the similarity in wood surfaces on different parameters compared to the experts' initial sorting (Table 1) and the selection based on the consumers' judgements. Moreover, according to Bumgardner et al. (2009), consumers and retailers use deviating cues (keywords) to evaluate character-marked wood surfaces.

Given the great natural variety of the presented material in our study, the reduction to (merely) seven distinctively different visual classes could prove to be relevant for marketing purposes in meeting different consumer preferences. In light of the fact that consumers differ in their subjective evaluation of wood surfaces and that the industry also has premium grades which feature mostly clear surfaces, it seems clear that different visual aspects of wood can affect people's appreciation of it. This is also supported by the findings of Donovan and Nicholls (2003) who found market opportunities for wood cabinet doors that contained slightly more character marks than fewer. This, however, is only one specific visual aspect in wood. Small-sized character marks and small knots are

Table 4 Size of latent classes (count); percentage of the total number of respondents (423) and ranking of the seven images within each latent class (LC)

\begin{tabular}{llllllll}
\hline Count (\%) & LC1 & LC2 & LC3 & LC4 & LC5 & LC6 & LC7 \\
& $37(8.7)$ & $57(13.5 \%)$ & $64(15.1 \%)$ & $53(12.5 \%)$ & $48(11.3 \%)$ & $73(17.3 \%)$ & $91(21.5 \%)$
\end{tabular}

Ranking results

\begin{tabular}{|c|c|c|c|c|c|c|c|c|c|c|c|c|c|c|}
\hline & Rank & Mean & Rank & Mean & Rank & Mean & Rank & Mean & Rank & Mean & Rank & Mean & Rank & Mean \\
\hline Image 1 & 2 & 3.14 & 2 & 3.24 & 2 & 2.88 & 7 & 5.22 & 1 & 2.33 & 7 & 7.00 & 1 & 1.00 \\
\hline Image 3 & 1 & 2.66 & 7 & 5.24 & 3 & 3.00 & 5 & 4.69 & 5 & 3.96 & 6 & 4.95 & 3 & 3.75 \\
\hline Image 4 & 5 & 4.00 & 1 & 2.83 & 6 & 5.27 & 6 & 4.94 & 2 & 3.31 & 4 & 3.78 & 2 & 3.69 \\
\hline Image 6 & 4 & 3.43 & 5 & 4.22 & 1 & 1.78 & 2 & 3.16 & 3 & 3.44 & 5 & 3.88 & 4 & 4.05 \\
\hline Image 8 & 7 & 7.00 & 4 & 4.19 & 5 & 5.22 & 1 & 2.41 & 4 & 3.80 & 1 & 1.82 & 7 & 5.90 \\
\hline Image 10 & 6 & 4.37 & 3 & 3.85 & 7 & 5.73 & 4 & 4.06 & 7 & 6.82 & 2 & 3.25 & 6 & 5.23 \\
\hline Image 12 & 3 & 3.4 & 6 & 4.43 & 4 & 4.13 & 3 & 3.53 & 6 & 4.33 & 3 & 3.33 & 5 & 4.39 \\
\hline
\end{tabular}

Rankings from $1=$ rank 1 to $7=$ rank 7. Top and lowest ranked images are highlighted in bold and italics, respectively 
Fig. 3 Average ranking of tested images for the seven extracted latent classes $(L C)$, from rank $1=$ 'like most' to rank $7=$ 'like least'. Top and lowest ranked images are highlighted with labels. The final ranking is to be interpreted in a equidistant, discrete scale (see Table 4) as well as the ranking data is analysed in a latent class analysis

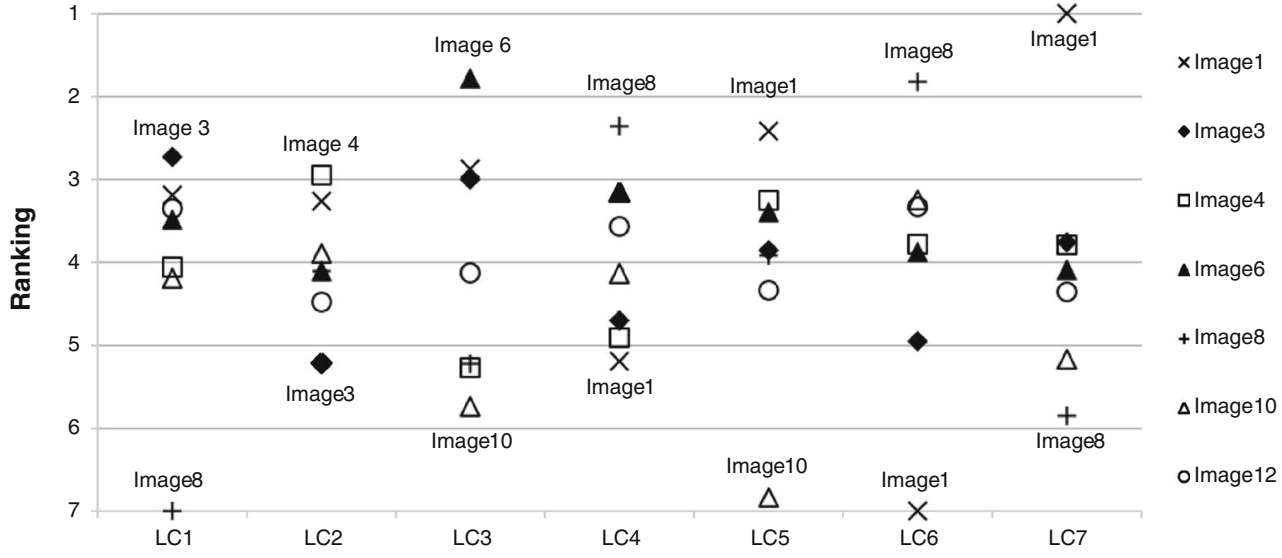

another visual wood aspect which is found to be preferred by consumers in hardwood furniture by Bumgardner et al. (2001).

It must be stated that the influence on the initial experts' sorting (Table 1) of single floor boards (board level) in contrast to the consumers' assessment of floor samples (floor level) is not fully explored in this study. Nevertheless, seven out of 15 visual classes were identified as unique based on the respondents' evaluations (76\% self-evaluated 'non-experts') which supports the assumption that the scientific experts' sorting in this study represents a high resolution of diverse visual wood features (cp. Hoibo and Nyrud 2010). The survey respondents on the other hand helped approach a (reduced) consumer oriented range of distinct visual aspects of wood surfaces from spruce and provide an empirical base towards a consumer preference study.

Configuring the floor samples out of single boards was carried out in a way to achieve an optically balanced image within the floor sample, based on earlier findings regarding visual homogeneity (Nyrud 2008) and the avoidance of mismatching features (Broman 1995b). It can be expected that making floor samples with the same boards but in different composition with regard to the position of the boards to each other may lead to a different visual judgement by the consumers. To study this effect, a greater number of respondents with a greater number of alternative images would be necessary. However, Deutsken et al. (2004) found that in online surveys, a shorter time needed for completion (15 to $30 \mathrm{~min}$ ) attracts more responses than a longer time (30 to $45 \mathrm{~min}$ ). From practical experience, we can confirm these findings and assume that completion should not exceed $10 \mathrm{~min}$; otherwise, uncompleted responses are common. Consequently, this consideration limits the number of images that can be tested in a survey. This aspect needs further research so that alternative inquiry techniques may be used.

Based on the (reduced) number of seven visual floor image classes, a preference study was carried out in an online experiment with 423 respondents. Validation studies can help to substantiate the findings and hypothetical conclusions made and better represent what is perceived among consumers in general. By applying latent class analysis in this study, it was possible to group the individual judgements into seven consumer classes. Every class contained between 8.7 and $21.5 \%$ of the total number of respondents. Five out of the seven presented floor images were top ranked (i.e. 'liked most') in at least one consumer group, revealing preferences for distinct wood aesthetics. The fact that people have chosen five out of seven different images as their top preference opens the possibility of consumer group-specific marketing even regarding the 'extreme' knotty surfaces. In the conventional floor panel production, these surfaces would be rejected due to their 'surface defects', e.g. big knots. Besides effects that relate to knot features, grain orientation may also be relevant in evaluating wood surfaces according to personal preference. This can be observed by comparing image 3 and image 6 which apparently both received a rank 1 (in LC1 and LC3) featuring small black knot features, but differences can be identified in 'opposite' grain orientations (vertical vs. flat grain). A similar effect can be observed between image 4 (rank 1 in LC2) and image 8 (rank 1 in LC4 and LC6) where big knots are dominant features but grain orientation is of opposite orientation.

Concerning knot features, Broman et al. (2008) presented to consumers eight pine floor samples of different appearance whose features ranged from 'rather few, small black knots' to 'larger sound knots'. For both extremes, there were people that liked and disliked them. This was expressed in a bimodal distribution where the highest frequencies could be found for both the highest ranks and the lowest ranks, indicating positive and negative preferences. This was also observed likewise in our study for the images 1 and 8 (Table 2) which represent clear surfaces with rift grain and surfaces with large sound knots with flat grain, respectively. A majority of $63 \%$ of the respondents had preferences for these 'extremes' (33\% for image 1 and $30 \%$ for image 8 ). 


\section{LC1}

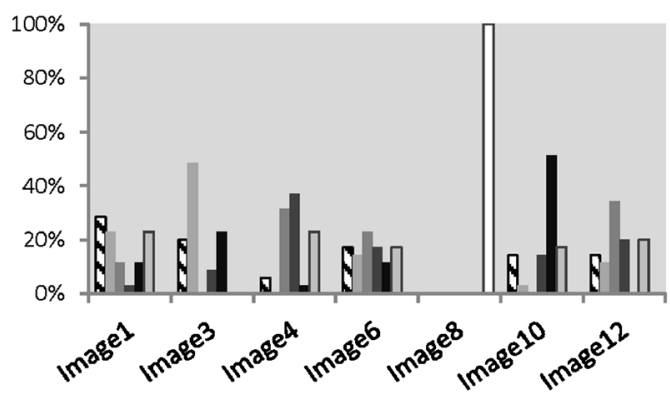

LC3 $100 \%$

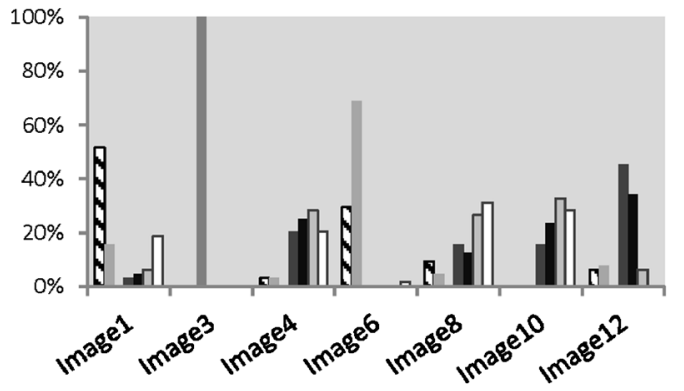

LC5

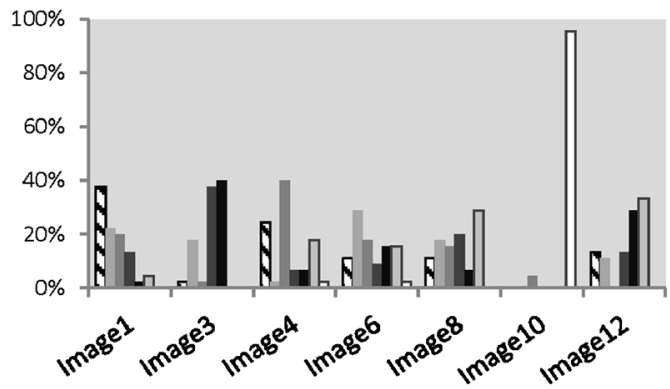

LC7 $100 \%$

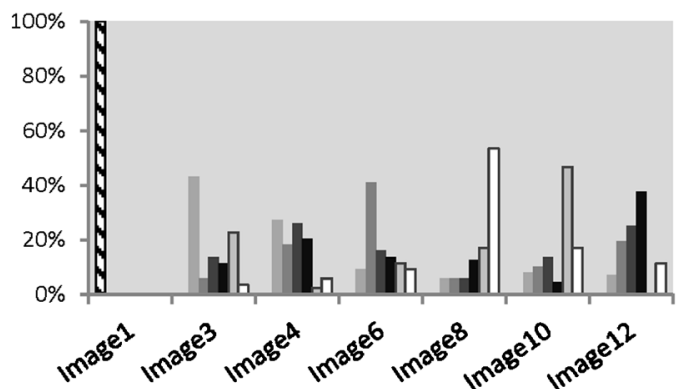

LC2

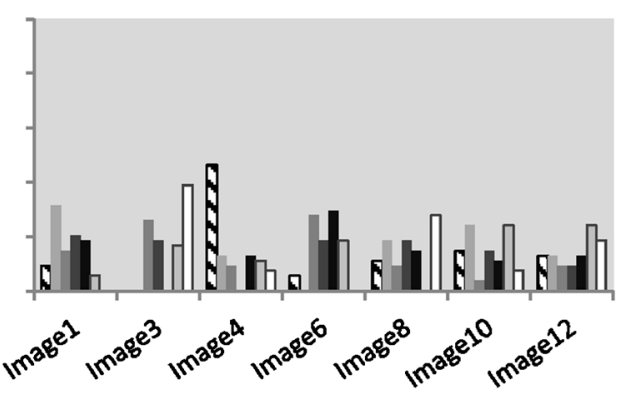

LC4

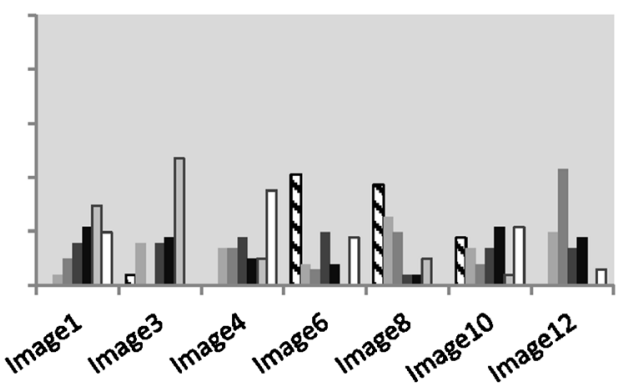

LC6
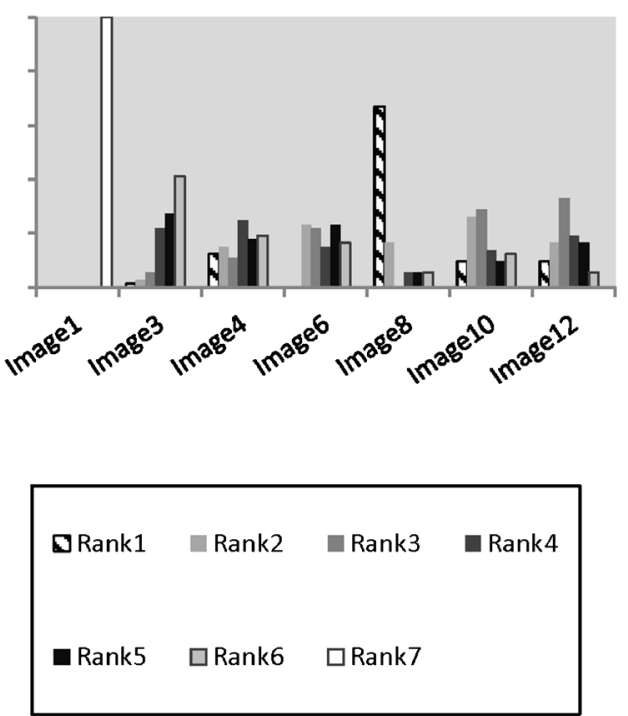

Fig. 4 The results for seven different floor sample images ranked into personal preference order led to seven different consumer groups which were determined by latent class analysis. The rank frequency distributions are presented for each respective consumer group (latent class - LC1 to LC7)

Another smaller consumer group (LC3, $15 \%$ ) had a clear preference for image 6 . Image 6 features small black knots and flat grain (Fig. 3). In this group, the highest agreement in preference was found for the images 3 and 6 upon the ranks 3 and 2, respectively (Fig. 4). Two out of seven image classes received only middle or lower ranks (image 10 with visible pith and image 12 with small sound knots) possibly indicating marketing problems for such surfaces (Fig. 3).

Three out of the seven consumer groups (LC1, LC2 and LC4) showed a rather vague or indifferent judgement towards all presented floor images, which could be interpreted as an overall low acceptance of spruce wood floors in general. Moreover, the rather unclear ranking profiles in LC2 and
LC4 indicate rather diverse judgements between the class members (Fig. 4). This is supported by the fact that a low degree of agreement in ranking order was found especially within LC4 where, for instance, the first rank was given to the images 6,8 and 10 .

A more differentiated analysis of the judgements according to social parameters (gender, age, professional background, attitude towards wood in general) did not reveal significant differences. This is perhaps due to the relatively small number of respondents and possibly also due to a bias in their status (people with 'wood-related' background represented 56.3\%). Differences in gender were found by Brinberg et al. (2007) and Donovan and Nicholls (2003)). They found that males 
prefer a higher level of character marks in kitchen furniture. Bumgardner et al. (2001) found that retailers of wood household furniture tend to prefer clear surfaces. In this context, small knots were more favoured than surfaces with large knots.

Results from this exploratory study have not given a representative picture from a randomly drawn sample (all completed responses were analysed) but the two online surveys received responses from around Germany. The ratio of response to non-response is another critical aspect that limits representation. It is therefore unknown how many potential respondents refused to participate and for what reasons. With regard to differences affected by socio-demographic variables, such effects must specifically be examined in more detail. A sample size of 500 to 1000 would be optimal in future studies.

\section{Conclusion}

The results of this study indicate different preferences regarding different aesthetics of wood surfaces. For a successful marketing of wood in the high-end product segment, visual surface characteristics are decisive factors. Wood surfaces from the same species show a high natural variability in aesthetic performance and consumer preferences also vary to a great extent.

Industry grading and sorting procedures are in many cases based on technical parameters which do not necessarily reflect the consumer preferences. Consumers look at and judge wood surfaces differently and regard them as similar, even if they show different technical features (e.g. knots, grain orientation). This allows the great natural variety to be reduced by creating similarity classes which in turn reduces complexity with regard to marketing. For the example of spruce wood floors, seven 'similarity classes' could be identified based on this online survey.

Seven different consumer groups with distinct preference profiles could be identified when using a pairwise preference test and latent class analysis. Five consumer groups showed clear agreement of ranking certain image classes, which provides important information about opportunities in market segmentation. Two consumer groups showed relatively vague responses about their preferences (medium or lower ranks) indicating less appreciation for the presented variety of wood appearances. Furthermore, the consumer groups with less pronounced preference profiles might offer opportunities for standard market segments because they reflect rather heterogeneous preferences.

Regarding the preferred images, five out of the seven image classes presented were identified to be the most preferred. One main effect could be identified that depicts opposing preferences regarding the most 'extreme' visual characteristics. A majority of the respondents tends to prefer clear surfaces or surfaces with big sound knots that are supposed to represent the most visually extreme features. It is interesting that people who prefer the one or the other extreme tend to dislike the opposite image which also indicates alternative market segments.

Results from this study indicate that consumers place their preferences differently when examining the same visual stimuli presented. Differences between consumers regarding socio-demographic and professional attributes are recommended to be examined in detail, after these did not indicate differences in this study. Nevertheless, the findings can provide relevant clues for further research referring to consumers' perceptions and preferences of wood and can also help the wood processing industries developing a consumer preference oriented production of visible high-end wood product surfaces. Besides advanced capabilities with existing optical two-dimensional board surface inspection, recent developments in three-dimensional log inspection and production optimization with the help of X-ray CT technology have been proposed (Breinig et al. 2014; Longuetaud et al. 2012) which may assist in developing a production process oriented on consumer preferences, predicting, for instance, preferred knot features and grain orientation on wood product surfaces, thereby also optimizing material usage.

Acknowledgments We would like to thank the sawmill company Echtle in Nordrach, Germany, and the people there who helped to process our material from the logs to floor boards and gave us access to all production lines including digital scanning data. We would also like to extend our thanks to our technical staff Erwin Hummel and Uwe Uhlich at the Chair of Forest Utilization as well as to the team of Lorenz Breinig, Franka Brüchert and Udo H. Sauter at FVA Baden-Württemberg in the Division of Forest Utilization for their tremendous support.

Funding This study is part of the research project 'What makes wood so attractive? Transforming people's emotions into material characteristics' which is supported by contract research 'Internationale Spitzenforschung II' of the Baden-Württemberg Stiftung.

\section{References}

Akaike H (1987) Factor analysis and AIC. Psychometrika 52:317-332. doi:10.1007/BF02294359

Breinig L, Leonhart R, Broman O, Manuel A, Brüchert F, Becker G (2014) Classification of wood surfaces according to visual appearance by multivariate analysis of wood feature data. J Wood Sci. doi: 10.1007/s10086-014-1410-6 (Accepted for publication in Journal of Wood Science)

Brinberg D, Bumgardner M, Daniloski K (2007) Understanding perception of wood household furniture: application of a policy capturing approach. For Prod J 57:21-26

Broman NO, Nyström J, Oja J (2008) Modelling the connection between industrially measured raw material properties and end user preferences: part 2. Results from preference studies. In: Peltola H (ed.) 6th Workshop on Connection between Forest Resources and Wood Quality: Modelling approaches and simulation software, IUFRO Working Party 5.01.04 Wood Quality Modelling, Koli, Finland, 8 p 
Broman NO (1996) Two methods for measuring people's preferences for Scots pine wood surfaces: a comparative multivariate approach. Mokuzai Gakkaishi 42:130-139

Broman NO (1995a) Attitudes toward Scots pine wood surfaces: a multivariate approach. Mokuzai Gakkaishi 41:994-1005

Broman NO (1995b) Visual impressions of features in Scots pine wood surfaces: a qualitative study. Forest Prod J 45:61-66

Bumgardner M, Nicholls D, Barber V (2009) Character-marked furniture made from red alder harvested in southeast Alaska: product perspectives from consumers and retailers. Can J For Res 39:2450-2459. doi:10.1139/X09-154

Bumgardner M, Bush R, West C (2001) Knots as an incongruent product feature: a demonstration of the potential for character-marked hardwood furniture. J Ins Wood Sci 15:327-336

Deutsken E, de Ruyter K, Wetzels M, Oosterveld P (2004) Response rate and response quality of internet-based surveys: an experimental study. Mark Lett 15:21-36

DIN (2002) DIN EN 1611-1:2002-11: Sawn timber - Appearance grading of softwood - Part 1: European spruces, firs, pines, Douglas fir and larches; German version EN 1611-1:1999 + A1:2002. Deutsches Institut für Normung e.V, Berlin

Donovan G, Nicholls D (2003) Consumer preferences and willingness to pay for character-marked cabinets from Alaska birch. Forest Prod J 53:27-32. doi:10.1139/X09-154

Geiser C (2011) Data analysis with Mplus - methodology in the social sciences. Guilford, New York

Gold S, Rubik F (2009) Consumer attitudes towards timber as a construction material and towards timber frame houses - selected findings of a representative survey among the German population. $\mathrm{J}$ Cleaner Prod 17:303-309. doi:10.1016/j.jclepro.2008.07.001

Hair JF, Black WC, Babin BJ, Anderson RE (2010) Multivariate data analysis. A global perspective. 7th Edition, Pearson Education, Upper Saddle River N.J., London

Hoibo O, Nyrud AQ (2010) Consumer perception of wood surfaces: the relationship between stated preferences and visual homogeneity. J Wood Sci 56:276-283. doi:10.1007/s10086-009-1104-7

IBM Corp. Released (2013) IBM SPSS Statistics for Windows, Version 22.0. IBM Corp., Armonk, New York

Jöreskog KG (1993) Testing structural equation models. In: Bollen KA, Long JS (ed) Testing structural equation models . Newbury Park: Sage, pp 294-317

Kretschmann DE (2010) Mechanical Properties of Wood. In: Ross RJ (ed) Wood handbook - Wood as an engineering material. USDA For Serv, Forest Products Laboratory, WI: Madison, Gen Tech Rep FPLGTR-190. 508 p

Kruskal JB (1964) Multidimensional scaling by optimizing goodness of fit to a nonmetric hypothesis. Psychometrica 9:1-27. doi:10.1007/ BF0228956

Longuetaud F, Mothe F, Kerautret B, Krähenbühl A, Hory L, Leban JM, Debled-Rennesson I (2012) Automatic knot detection and measurements from X-ray CT images of wood: a review and validation of an improved algorithm on softwood samples. Comput Electron Agric 85:77-89. doi:10.1016/j.compag.2012.03.013

Marchal R, Mothe F (1994) Appreciation of oak wood (Quercus robur L, Quercus petraea Liebl) for the French consumer and wood professionals. Ann For Sci 51:213-231. doi:10.1051/forest:19940302

Muthén LK, Muthén BO (1998-2011) Mplus User's Guide. 6th Edition. Muthén\&Muthén, Los Angeles, CA

Nicholls DL, Barber V (2010) Character-marked red alder lumber from southeastern Alaska: profiled panel product preferences by residential consumers. Forest Prod J 60:315-321. doi: 10.13073/00157473-60.4.315

Nordvik E, Schütte S, Broman NO (2010) People's perceptions of the visual appearance of wood flooring. A Kansei engineering approach. Forest Prod J 59:67-74

Nyrud AQ, Bringslimark T (2010) Is interior wood use psychologically beneficial? A review of psychological responses toward wood. Wood Fiber Sci 42:202-218

Nyrud AQ (2008) Product attributes affecting consumer preference for residential deck materials. Can J For Res 38:1385-1396. doi:10. 1139/X07-188

Pakarinen T (1999) Success factors of wood as a furniture material. Forest Prod J 49:79-85

Ramananantoandro T, Ramanakoto MF, Rajemison AH, Eyma F (2013) Relationship between density and aesthetic attributes of wood and preference of Malagasy consumers. Ann For Sci 70:649-658. doi: 10.1007/s13595-013-0299-3

Rice J, Kozak R, Meitner M, Cohen D (2006) Appearance wood products and psychological well-being. Wood Fiber Sci 38:644-659

Ridoutt BG, Ball RD, Killerby SK (2002) Wood in the interior office environment: effects on interpersonal perception. For Prod J 52:2330

Rost J (2006) Latent-Class-Analyse. In: Petermann F, Eid M (eds) Handbuch der psychologischen Diagnostik. Hogrefe, Göttingen/ Seattle, pp 275-287

Scheer D, Hoffmann E, Rubik F (2008) Mit Holz in die Zukunft? Eine Branche am Scheideweg. Forschungszentrum Jülich. http:// www.ioew.de/uploads/tx_ukioewdb/ZUFO- Broschuere.pdf Accessed 11 July 2014

Schwarz G (1978) Estimating the dimension of a model. Ann Stat 6:461464

Weinfurter S, Hansen EN (1999) Softwood lumber quality requirements: examining the supplier/buyer perception gap. Wood Fiber Sci 31: 83-94

Wiedenbeck J, Wiemann M, Alderman D, Baumgras J, Luppold W (2004) Defining hardwood veneer log quality attributes. USDA For Serv, Newtown Square, Penn Gen Tech Rep NE-313, 20 p

Young FW, Lewyckyj R (1979) ALSCAL-4 User's Guide: a guide for users of ALSCAL-4. A nonmetric multidimensional scaling and unfolding program with several individual differences options, University of North Carolina, $128 \mathrm{p}$ 